DR. JULIE ELAINE BAUMAN (Orcid ID : 0000-0002-1398-6636)

DR. EVERETT E VOKES (Orcid ID : 0000-0002-8645-8068)

Article type :Original Article

\title{
A randomized phase II network trial of tivantinib plus cetuximab versus cetuximab in patients with recurrent/metastatic head and neck squamous cell carcinoma.
}

Running Title: Tivantinib + cetuximab vs cetuximab in HNSCC

Sara Kochanny, BA ${ }^{1}$; Francis. P. Worden, MD²; Douglas Adkins, $\mathrm{MD}^{3}$; Dean Lim, MD; Julie E. Bauman, MD5; Stephanie A. Wagner, MD' ${ }^{6}$; Ryan J. Brisson, BS7; Theodore Karrison, $\mathrm{PhD}^{1}$; Walter M. Stadler, $\mathrm{MD}^{1}$; Everett E. Vokes, $\mathrm{MD}^{1 *} ; \&$ Tanguy Y. Seiwert, $\mathrm{MD}^{8}$

\section{Affiliations:}

1. University of Chicago Medicine and Comprehensive Cancer Center, Chicago, Illinois

2. Comprehensive Cancer Center, University of Michigan, Ann Arbor, Michigan

3. Siteman Cancer Center, Washington University, St. Louis, Missouri

4. Comprehensive Cancer Center, City of Hope, Duarte, California

5. University of Arizona Cancer Center, Phoenix, Arizona

6. Simon Cancer Center, Indiana University, Indianapolis, Indiana

7. Oakland University William Beaumont School of Medicine, Rochester, Michigan

8. Johns Hopkins University, Baltimore, Maryland

This is the author manuscript accepted for publication and has undergone full peer review but has not been through the copyediting, typesetting, pagination and proofreading process, which may lead to differences between this version and the Version of Record. Please cite this article as doi: 10.1002/CNCR.32762

This article is protected by copyright. All rights reserved 


\section{*Correspondence to:}

Dr. Everett E. Vokes,

Department of Medicine

The University of Chicago Medicine

5841 S. Maryland Avenue, MC2115

Chicago, IL 60637, USA

Telephone: +1-773-702-9306

E-mail: evokes@medicine.bsd.uchicago.edu

\section{()}

Acknowledgment of Funding Support: This work was supported by NCI CTEP, ArQule Pharmaceuticals, and a grant from the Comprehensive Cancer Center at the University of Chicago.

\section{Conflict of Interest Statements:}

Tanguy Y. Seiwert has received research funding from Bristol-Myers Squibb, Jounce Therapeutics and Merck as well as honoraria from Aduro, Astra-Zeneca, Bayer, Bristol-Myers Squibb, Celgene, Genentech, Innate, Nanobiotix and Merck.

Everett E. Vokes has a consultant/advisory role with AbbVie, Amgen, AstraZeneca, Biolumina, Bristol-Myers Squibb, Celgene, Eli Lilly, EMD Serono, Genentech, Merck, Novartis and Regeneron.

Francis P. Worden has a consultant/advisory role with Merck, Cue Biopharma, Bayer, and Loxo Oncology as well as grants/research funding from Bristol-Meyers Squibb, Merck, Cue Biopharma, Eisai, Eli Lilly, Loxo Oncology and Pfizer.

Douglas Adkins has a consultant/advisory role with Pfizer, Eli Lilly, Merck, Celgene, Cue Biopharma, and Loxo Oncology as well as research funding from Phase 2 Consortium during the 
study, as well as grants/research funding from Pfizer, Eli Lilly, Merck, Novartis, Celgene, Astra Zeneca, Atara, Blueprint Medicine, CellCeutix, Celldex, Enzychem, Gliknik, Bristol-Meyers Squibb, Kura, Medimmune, Exelixis, Innate, Matrix Biomed, Cue Biopharma, and Sensei, outside the submitted work.

Julie E. Bauman has a consultant/advisory role with Astra Zeneca, EMD Serono, and Merck, as well as grants/research funding from Aveo, Bristol-Myers Squibb, Celldex, Cue Biopharma, Moderna, and Novartis outside of the submitted work.

All remaining authors declare that they have no competing interests.

Author Contribution Statement: Sara Kochanny: Data acquisition, statistical analysis, manuscript writing and preparation. Francis P. Worden: Patient enrollment. Douglas Adkins: Patient enrollment. Dean Lim: Patient enrollment. Julie E. Bauman: Patient enrollment. Stephanie A. Wagner: Patient enrollment. Ryan J. Brisson: Data acquisition, manuscript editing. Theodore Karrison: Formal statistical analysis. Walter M. Stadler: Trial management and advisor. Everett E. Vokes: Patient enrollment, methodology. Tanguy Y. Seiwert: Conceptualization, methodology, patient enrollment, manuscript writing and preparation.

Acknowledgements: We thank all of the patients and their families for their participation, as well as the clinical and research staffs at the participating institutions for their hard work. We should also like to thank Shanda Lentz for her contributions while preparing this manuscript. We want to thank the following faculty for their contributions to this trial and entering their patients, Kelly K. Curtis, Katharine A.R. Price, Ammar Sukari, Barbara J. Gitlitz, Mark Agulnik, Bruce Brockstein, Chandra P. Belani, James L. Wade, and Bethany G. Sleckman.

Precis for use in the Table of Contents: In recurrent/metastatic HNSCC, tivantinib + cetuximab did not significantly improve tumor response rate or overall survival compared to cetuximab alone but increased toxicity. HPV/p16-positive patients had a $0 \%$ response rate within the study, consistent with other reports that EGFR inhibitors appear to be less active in HPV/p16 positive metastatic HNSCC patients. 


\section{Abstract:}

Background: MET signaling is a well-described mechanism of resistance to anti-EGFR therapy, and MET over-expression is common in head and neck squamous cell carcinomas (HNSCC). This trial compared the oral MET inhibitor tivantinib (ARQ197) in combination with cetuximab (TC) versus cetuximab monotherapy (C) in patients with recurrent/metastatic HNSCC.

Patients and methods: 78 evaluable cetuximab-naïve platinum-refractory HNSCC patients were enrolled, 40 on the TC arm, and 38 on the cetuximab control arm (stratified by HPV-status). Tivantinib was given orally $360 \mathrm{mg}$ twice a day, cetuximab $500 \mathrm{mg} / \mathrm{m} 2$ iv biweekly. Primary outcome was response rate (RECIST 1.1), secondary outcomes included progression free and overall survival (PFS, OS). After progression on the control arm, tivantinib monotherapy was optional.

Results: The response rate in the TC arm was $7.5 \%(\mathrm{~N}=3$, one $\mathrm{CR})$, and $7.9 \%(\mathrm{~N}=3)$ in the $\mathrm{C}$ arm (NS). Median PFS in both arms was 4 months (NS), median OS 8 months (NS). Both treatments were well tolerated with a trend towards increased hematological toxicities in the TC arm (12.5\% with grade 3 leukopenia). Response rate in $31 \mathrm{HPV} / \mathrm{p} 16$-positive pts was $0 \%$ in both arms, while the response rate in HPV-negative pts was $12.7 \%(12.5 \%(\mathrm{TC}), 13 \%(\mathrm{C}))$. Fifteen patients received tivantinib monotherapy, no responses were observed.

Conclusions: Tivantinib + cetuximab does not significantly improve response rate or survival compared to cetuximab alone, but increases toxicity in an unselected HNSCC population. Cetuximab responses appear limited to HPV-negative HNSCC patients. MET-aberration focused trials for HNSCC, and use of higher-potency, selective MET inhibitors remain of interest.

Keywords: head and neck squamous cell carcinoma, c-MET, tivantinib, cetuximab, recurrent disease, metastatic disease

Text pages count: 20

Tables count: 3

This article is protected by copyright. All rights reserved 
Figures count: 3

Supporting files for publication count: 0

\section{Introduction:}

The prognosis of patients with recurrent or metastatic head and neck squamous cell carcinoma (HNSCC) after failure of first-line platinum containing chemotherapy remains poor with an estimated survival of 6-8 months[1]. In platinum-refractory patients, options are limited and include cytotoxic chemotherapy, anti-EGFR therapy with cetuximab, and since 2016, immune checkpoint inhibition[2]. Objective responses to cytotoxic chemotherapy are generally $\leq 10 \%$ after failure of first-line therapy. While checkpoint inhibition alone or in combination with chemotherapy is active, objective response rates are modest ranging from $13.3-18 \%$ [3]. Thus, optimizing targeted therapy approaches remains of interest.

Epidermal growth factor receptor (EGFR) is expressed at high levels in a majority of head and neck cancers and expression is associated with poor prognosis[4]. Treatment with the anti-EGFR antibody cetuximab (alone or in combination with chemotherapy) is approved in the United States for patients with recurrent/metastatic disease[1, 5, 6]. Despite frequent expression in HNSCC, the objective response rate to cetuximab monotherapy is only $10-13 \%$ [5], and $36 \%$ in combination with chemotherapy[1]. Given the modest clinical activity, investigation of combination approaches that target escape signaling pathways has been of interest $[7,8]$ in order to improve efficacy.

The MET receptor tyrosine kinase is overexpressed in HNSCC[9]. Preclinical data in HNSCC support co-targeting of EGFR and MET and reveal synergy in models with extensive signaling crosstalk[10, 11].

Tivantinib (ARQ 197), is an oral, non-competitive MET inhibitor that has shown antitumor efficacy in several diseases[12]. Tivantinib has broad spectrum anti-tumor activity both as a single agent and in combination in preclinical studies in HNSCC cell lines[13, 14]. Clinical studies of tivantinib combined with EGFR inhibition have been well tolerated[15].

Given the frequency and targetability of MET in HNSCC, the active and well-tolerated toxicity profile of tivantinib, and the documented synergy of EGFR and MET in HNSCC preclinical models, we proposed to study the EGFR inhibitor cetuximab and the MET inhibitor ARQ 197 (tivantinib) in combination in a randomized phase 2 study of cetuximab + tivantinib 
versus cetuximab monotherapy to assess possible synergy in patients with platinum-refractory HNSCC.

\section{Methods:

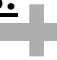 \\ Patient population}

Patients enrolled were $\geq 18$ years of age with histologically or cytologically confirmed HNSCC not amenable to curative intent therapy. Both HPV-positive (HPV+) and HPV-negative (HPV-) patients were eligible, with HPV status determination required prior to enrollment. Patients were required to have measurable disease as per Response Evaluation Criteria in Solid Tumors (RECIST v1.1), Eastern Cooperative Group Performance Status (ECOG) 0-1, normal organ and marrow function, a life expectancy of greater than 8 weeks, the ability to swallow pills and no active cardiac disease (such as history of congestive heart failure, active coronary artery disease, uncontrolled cardiac arrhythmia, uncontrolled hypertension, myocardial infarction within 6 months of enrollment). Patients who received treatment with an EGFR inhibitor in the curative intent setting remained eligible, but patients who were treated in the palliative intent setting with an EGFR or MET inhibitor or who received more than 2 palliative cytotoxic treatments were ineligible. Patients with active brain metastases, pregnancy, comorbidities interfering with therapy or survival, or other malignancies within 3 years were excluded. Written informed consent was obtained from every patient prior to enrollment. Patients were enrolled across 16 institutions, a full list available on www.clinicaltrials.gov (Clinical Trials.gov Identifier: NCT01696955).

\section{Investigational treatment}

Prior to treatment, patients underwent cross-sectional imaging, laboratory evaluation, electrocardiogram, and full physical examination. Patients were randomized 1:1 using the method of permuted blocks, and stratified by HPV status. Any commonly used HPV test (e.g. p16 IHC, ISH etc.) was acceptable; in the case of discrepancies between p16 \& ISH, the ISH result was used. Any HPV(+) by p16 alone, regardless of primary site, was assigned to the HPV+ group. Cetuximab was given $500 \mathrm{mg} / \mathrm{m}^{2}$ intravenously every two weeks and tivantinib $360 \mathrm{mg}$ 
tablet self-administered orally twice daily. Patients who progressed on the cetuximab-only arm had the option to receive tivantinib single agent therapy (orally BID on days 1-28) afterwards. Cycle length was 4 weeks, and imaging occurred every 8 weeks.

\section{Endpoints and Statistical Methods}

The primary endpoint was objective response rate (ORR), defined as the percentage of patients whose best response from baseline to nadir was either a complete (CR) or partial response (PR), according to RECIST v1.1. All randomized patients who received study drug were included in response rate analysis; patients who did not undergo a first imaging evaluation for any reason were counted as non-responders. ORRs between the two arms were compared using Fisher's exact test. Statistical power calculations indicated that a sample size of N=38 patients per arm would achieve $80 \%$ power to detect a difference of $12 \%$ versus $35 \%$ between the cetuximab and combination treatment arms, using a one-sided test at the alpha $=0.10$ significance level.

Secondary endpoints included PFS, OS, tumor shrinkage at 8 weeks, and single agent activity of tivantinib after failure of cetuximab (descriptive). PFS was defined as time from randomization until disease progression, death from any cause, or date last known as progression-free; OS was the time from randomization until death or date last known alive. Kaplan-Meier curves were generated for PFS and OS and the treatment arms were compared via logrank tests. Tumor shrinkage at 8 weeks was compared using a two-sample t-test. Single agent activity of tivantinib was described by the ORR and adverse event profiles of patients who received tivantinib monotherapy.

All toxicities were graded according to the US National Cancer Institute Common Toxicity Criteria (version 4.0). Adverse events reported in arm $\mathrm{C}$ were prior to any crossover to tivantinib monotherapy.

\section{$\underline{\text { Results: }}$}

81 patients were enrolled from 2012 until 2014, and 78 patients started treatment $(\mathrm{N}=78)$ (Table 1, Figure 1). 40 patients were randomized to the tivantinib + cetuximab (TC) arm, and 38 randomized to the cetuximab (C) arm. Of the 81 enrolled patients, three never received study treatment and were not included in the response analysis (one found to be ineligible, one 
insurance denial, one withdrew consent prior to starting). Among 78 patients who received treatment 11 patients (TC, $N=7 ; \mathrm{C}, N=4)$ came off treatment for an adverse event, death, withdrawal, or crossover prior to first evaluation, and were included in the primary outcome analysis as non-responders.

After progression on the cetuximab control arm, fifteen patients went on to receive single-agent tivantinib. Patient characteristics are shown in Table $\mathbf{1}$ and are similar between both treatment arms. Patients enrolled were primarily male (TC: $85.0 \%, \mathrm{C}: 84.2 \%$ ), with ages ranging from 35-90. Sixteen patients (40.0\%) were $\operatorname{HPV}(+)$ on the TC arm, and fifteen (39.5\%) were $\mathrm{HPV}(+)$ on the $\mathrm{C}$ arm. $70.0 \%$ of patients on the TC arm had $\geq 2$ prior therapies, compared to $81.6 \%$ of patients on the $\mathrm{C}$ arm (NS).

\section{Response - Primary Endpoint}

Response rate was not significantly different between the two arms (Table 2): $7.5 \%$ (3/40 responses) on the TC arm and 7.9\% (3/38 responses) on the cetuximab arm $(P=1.0)$. On the TC arm, two patients had a partial response and one patient had a complete response $(\mathrm{CR}=2.5 \%$; $\mathrm{PR}=5.0 \%)$; on the cetuximab arm three patients had a partial response $(\mathrm{PR}=7.9 \%)$. For patients undergoing at least one imaging assessment, response of target lesions from baseline to nadir is described in the waterfall plot in Figure 2a. The most common reason for treatment discontinuation was progressive disease $(N=48,61.5 \%)$, followed by adverse events $(N=11$, $14.1 \%)$, study withdrawal $(N=6,7.7 \%)$, and death $(N=6,7.7 \%)$.

In a post-hoc subgroup analysis, the response rate in $31 \mathrm{HPV}(+) / \mathrm{p} 16$-positive $\mathrm{HNSCC}$ pts was $0 \%$ in both arms. The response rate in HPV(-) patients was $12.7 \%$ (TC:12.5\%, C:13\%).

\section{Secondary Endpoints - Single agent Tivantinib activity}

Patients on the cetuximab (C) control arm had the option to receive single agent tivantinib upon progression: 15 out of 38 patients received tivantinib alone. None of these patients showed tumor response to tivantinib monotherapy (ORR 0\%). 
Secondary Endpoints - Tumor shrinkage at 8 weeks

For the TC arm, the mean shrinkage was a $15.0 \%$ increase ( $N=32$, SD $34.7 \%$ ); for the C arm, the mean change was a $9.0 \%$ increase $(N=31, \mathrm{SD} 30.8 \%)(P=0.47)$. Waterfall plots are shown in Figure 2b.

Secondary Endpoints - Progression Free and Overall Survival

For the TC arm, median PFS was 3.5 months (95\% CI [1.8-3.9]); for the C arm, median PFS was 3.5 months (95\% CI [2.0-3.9])(Figure 3a) (logrank $P=0.99)$. For the TC arm, median OS was 7.4 months (95\% CI [4.7-10.3]); for the C arm, OS was 8.6 months (95\% CI [5.711.5])(Figure 3b) (logrank $P=0.58)$.

All-cause mortality rate while on study was $36 / 40(90 \%)$ on the TC arm and $35 / 38$ (92.1\%) on the Carm.

\section{Toxicity}

All 78 patients treated were evaluable for safety assessments. The most common grade $\geq 3$ adverse events (AEs) (occurring $>1$ patient) attributed as at least possibly related to study drug for both treatment arms are presented in Table 3. There were a total of 84 grade $\geq 3$ AEs reported on the TC arm among the 40 patients ( $N=43$ at least possibly related), and 53 on the $\mathrm{C}$ arm ( $N=23$ at least possibly related). Myelosuppression was observed on the TC combination arm only: Grade $\geq 3+$ myelosuppression occurred in $18 / 40$ patients (45\%), compared to $3 / 38$ (7.9\%) for the $\mathrm{C}$ arm.

There were two grade $5 \mathrm{AEs} /$ deaths attributed as possibly related to study drug: pneumonia/lung infection (TC), and one septic death while on tivantinib monotherapy. The patient on the TC arm was hospitalized with lung infection in the setting of febrile neutropenia 15 days after the first treatment with cetuximab and tivantinib; the patient's condition deteriorated and they died two weeks later. The patient who crossed over to tivantinib monotherapy from the $\mathrm{C}$ arm was admitted with severe hypoxia and persistent neutropenia, which worsened to hypoxic respiratory failure in the setting of neutropenic fever and pseudomonas sepsis.

Of the fifteen patients who went on to receive single-agent tivantinib, 4/15 (26.7\%) experienced a grade $\geq 3 \mathrm{AE}$, and $9 / 15(60.0 \%)$ experienced a grade $\leq 2 \mathrm{AE}$, the most common 
( $\geq 15 \%)$ were anemia, fatigue, decreased lymphocyte count, hypomagnesemia, and hypertension, each of which were reported in $3 / 15$ patients $(20 \%)$.

\section{Discussion:}

A randomized, multicenter study was performed to evaluate the role of adding the MET small molecular inhibitor tivantinib to anti-EGFR therapy with cetuximab based on preclinical data $[10,11]$ and data in other cancer types (NSCLC $[16,17])$ that MET inhibition synergizes with anti-EGFR therapy. However, this was a negative trial. The addition of tivantinib did not improve tumor response rate nor overall survival outcomes compared to cetuximab monotherapy in an unselected population of patients with recurrent/metastatic HNSCC. Furthermore, there was no single agent activity with tivantinib after cetuximab, although treatment was optional and hence may be subject to a selection bias. Importantly, toxicity from tivantinib was prominent in particular in the form of myelotoxicity with $45 \%$ of patients on the TC arm experiencing grade $\geq 3$ myelotoxicity (compared to $7.9 \%$ on the cetuximab arm). In addition, two possibly tivantinibrelated grade 5 events occurred ( 1 on TC arm, and 1 on tivantinib monotherapy). Toxicities typical for other selective MET or HGF inhibitors, e.g. ankle edema or renal toxicity were not observed. Henceforth, further development of tivantinib for HNSCC should not be pursued.

Interestingly, in a post-hoc exploratory subgroup analysis, we show a $0 \%$ ORR in $\mathrm{HPV}(+)$ patients on both arms, compared to $12.5 \%$ (TC)/ $13.0 \%$ (C) in $\mathrm{HPV}(-)$ patients, driven by cetuximab therapy[18]. These results are consistent with other reports that EGFR inhibitors, including cetuximab, appear to be less active in HPV/p16 positive HNSCC patients[6, 19, 20]. Comprehensive genomic analysis has revealed that EGFR gene amplification is common in $\operatorname{HPV}(-) \operatorname{HNSCC}$, whereas almost non-existent in $\operatorname{HPV}(+) \operatorname{HNSCC}[9,18,21]$. This evidence suggests that HPV $(+)$ HNSCC may not be a suitable population for anti-EGFR therapies.

Tivantinib may not be an ideal MET inhibitor. Tivantinib's mechanism of action as a non-competitive inhibitor is not fully understood: While its ability to bind and inhibit MET is well known and modest, tivantinib has also shown cytotoxic effects (i.e. tubulin binding) reminiscent of a spindle poison [22] and likely accounts for the myelotoxicity and lack of MET specific toxicities such as edema and renal toxicity[23, 24]. Tivantinib appears less selective than other MET inhibitors: its effects have been seen in the absence of MET expression and in populations of tumor cells not susceptible to MET inhibition [22, 25]. Single agent tivantinib did 
not show activity, in contrast to prior activity with foretinib, a dual MET/VEGFR inhibitor, in a similar population [26].

This study was performed in an unselected population, and no post-hoc MET expression analysis was pursued due to low response rates. A recent meta-analysis of tivantinib in solid tumor types (not including HNSCC) showed significant improvement in PFS \& OS in the METhigh subgroup but not the unselected population[15]. Selection for high-MET expressing HNSCC could be considered in the future.

Newer, more specific, higher potency MET inhibitors are currently being developed for use in MET exon14 skipping and higher-level MET amplified NSCLC with early promising data[24, 27]. Both exon 14 skipping and MET amplification have been reported in HNSCC, and while uncommon[9], they might provide a more selective way forward to investigate MET or dual MET/EGFR inhibition in HNSCC.

In conclusion, tivantinib + cetuximab did not significantly improve tumor response rate or overall survival compared to cetuximab alone but increased toxicity. No single agent tivantinib activity was witnessed. Given these results, further development of tivantinib in HNSCC should not be pursued. Cetuximab responses appeared to be limited to HPV(-) HNSCC patients, consistent with reports that EGFR inhibitors may be less effective in $\operatorname{HPV}(+) \operatorname{HNSCC}$. Future MET-aberration-focused trials should include HNSCC patients, and use of higherpotency, selective MET inhibitors remain of interest.

\section{References:}

1. Vermorken JB, Mesia R, Rivera F et al. Platinum-based chemotherapy plus cetuximab in head and neck cancer. N Engl J Med 2008; 359: 1116-1127.

2. Rischin D, Harrington KJ, Greil R et al. Protocol-specified final analysis of the phase 3 KEYNOTE-048 trial of pembrolizumab (pembro) as first-line therapy for recurrent/metastatic head and neck squamous cell carcinoma (R/M HNSCC). Journal of Clinical Oncology 2019; 37: 6000-6000.

3. Seiwert TY, Burtness B, Mehra R et al. Safety and clinical activity of pembrolizumab for treatment of recurrent or metastatic squamous cell carcinoma of the head and neck 
(KEYNOTE-012): an open-label, multicentre, phase 1b trial. Lancet Oncol 2016; 17: 956-965.

4. Grandis JR, Melhem MF, Gooding WE et al. Levels of TGF- $\alpha$ and EGFR Protein in Head and Neck Squamous Cell Carcinoma and Patient Survival. JNCI: Journal of the National Cancer Institute 1998; 90: 824-832.

5. Vermorken JB, Trigo J, Hitt R et al. Open-label, uncontrolled, multicenter phase II study to evaluate the efficacy and toxicity of cetuximab as a single agent in patients with recurrent and/or metastatic squamous cell carcinoma of the head and neck who failed to respond to platinum-based therapy. J Clin Oncol 2007; 25: 2171-2177.

6. Jelinek MJ, Vokes EE. Epidermal Growth Factor Receptor Blockade in Head and Neck Cancer: What Remains? Journal of Clinical Oncology 0: JCO.19.01981.

7. Engelman JA, Zejnullahu K, Mitsudomi $\mathrm{T}$ et al. MET amplification leads to gefitinib resistance in lung cancer by activating ERBB3 signaling. Science 2007; 316: 1039-1043.

8. Wheeler DL, Huang S, Kruser TJ et al. Mechanisms of acquired resistance to cetuximab: role of HËR (ErbB) family members. Oncogene 2008; 27: 3944-3956.

9. The Cancer Genome Atlas N, Lawrence MS, Sougnez C et al. Comprehensive genomic characterization of head and neck squamous cell carcinomas. Nature 2015; 517: 576.

10. Seiwert TY, Jagadeeswaran R, Faoro L et al. The MET receptor tyrosine kinase is a potential novel therapeutic target for head and neck squamous cell carcinoma. Cancer Res 2009; 69: 3021-3031.

11. Xu H, Stabile LP, Gubish CT et al. Dual blockade of EGFR and c-Met abrogates redundant signaling and proliferation in head and neck carcinoma cells. Clin Cancer Res 2011; 17: 4425-4438.

12. Eathiraj S, Palma R, Volckova E et al. Discovery of a novel mode of protein kinase inhibition characterized by the mechanism of inhibition of human mesenchymalepithelial transition factor (c-Met) protein autophosphorylation by ARQ 197. J Biol Chem 2011; 286: 20666-20676.

13. Munshi N, Jeay S, Li Y et al. ARQ 197, a Novel and Selective Inhibitor of the Human cMet Receptor Tyrosine Kinase with Antitumor Activity. Molecular Cancer Therapeutics 2010; 9: 1544-1553. 
14. Yap TA, Olmos D, Brunetto AT et al. Phase I Trial of a Selective c-MET Inhibitor ARQ 197 Incorporating Proof of Mechanism Pharmacodynamic Studies. Journal of Clinical Oncology 2011; 29: 1271-1279.

15. Zhang $\mathrm{H}, \mathrm{Bao} \mathrm{Z}$, Liao $\mathrm{H}$ et al. The efficacy and safety of tivantinib in the treatment of solid tumors: a systematic review and meta-analysis. Oncotarget 2017; 8: 113153113162.

16. Scagliotti G, von Pawel J, Novello S et al. Phase III Multinational, Randomized, DoubleBlind, Placebo-Controlled Study of Tivantinib (ARQ 197) Plus Erlotinib Versus Erlotinib Alone in Previously Treated Patients With Locally Advanced or Metastatic Nonsquamous Non-Small-Cell Lung Cancer. J Clin Oncol 2015; 33: 2667-2674.

17. Spigel DR, Edelman MJ, O'Byrne K et al. Results From the Phase III Randomized Trial of Onartuzumab Plus Erlotinib Versus Erlotinib in Previously Treated Stage IIIB or IV Non-Small-Cell Lung Cancer: METLung. J Clin Oncol 2017; 35: 412-420.

18. Szturz P, Budikova M, Vermorken JB et al. Prognostic value of c-MET in head and neck cancer: A systematic review and meta-analysis of aggregate data. Oral Oncol 2017; 74: 68-76.

19. Vermorken JB, Stohlmacher-Williams J, Davidenko I et al. Cisplatin and fluorouracil with or without panitumumab in patients with recurrent or metastatic squamous-cell carcinoma of the head and neck (SPECTRUM): an open-label phase 3 randomised trial. Lancet Oncol 2013; 14: 697-710.

20. Chau NG, Perez-Ordonez B, Zhang $\mathrm{K}$ et al. The association between EGFR variant III, HPV, p16, c-MET, EGFR gene copy number and response to EGFR inhibitors in patients with recurrent or metastatic squamous cell carcinoma of the head and neck. Head Neck Oncol 2011; 3: 11.

21. Keck MK, Zuo Z, Khattri A et al. Integrative analysis of head and neck cancer identifies two biologically distinct HPV and three non-HPV subtypes. Clin Cancer Res 2015; 21: 870-881.

22. Katayama R, Aoyama A, Yamori T et al. Cytotoxic activity of tivantinib (ARQ 197) is not due solely to c-MET inhibition. Cancer Res 2013; 73: 3087-3096. 
23. Patnaik A, Weiss GJ, Papadopoulos KP et al. Phase I ficlatuzumab monotherapy or with erlotinib for refractory advanced solid tumours and multiple myeloma. British journal of cancer 2014; 111: 272-280.

24. Hong DS, LoRusso P, Hamid O et al. Phase I Study of AMG 337, a Highly Selective Small-molecule MET Inhibitor, in Patients with Advanced Solid Tumors. Clinical Cancer Research 2019; 25: 2403-2413.

25. Comoglio PM, Giordano S, Trusolino L. Drug development of MET inhibitors: targeting oncogene addiction and expedience. Nat Rev Drug Discov 2008;7:504-716.

26. Seiwert T, Sarantopoulos J, Kallender H et al. Phase II trial of single-agent foretinib (GSK1363089) in patients with recurrent or metastatic squamous cell carcinoma of the head and neck. Investigational new drugs 2013; 31: 417-424.

27. Friese-Hamim M, Bladt F, Locatelli $\mathrm{G}$ et al. The selective c-Met inhibitor tepotinib can overcome epidermal growth factor receptor inhibitor resistance mediated by aberrant cMet activation in NSCLC models. American journal of cancer research 2017; 7: 962-972.

\section{Figure 1.}

Trial Schema and patient allocation.

\section{Figure 2.}

Waterfall plots for (a) best response from baseline to nadir and (b) early tumor shrinkage from baseline to week 8, measured by Response Evaluation Criteria In Solid Tumors (RECIST v1.1), for each arm.

\section{Figure 3.}

Kaplan-Meier survival curves for (a) median overall survival and (b) median progression-free survival for each arm. TC is the tivantinib + cetuximab arm (in blue), $\mathrm{C}$ is the cetuximab monotherapy arm (red). Tic marks denote censored observations. 
Tables:

Table 1. Clinical Patient Characteristics by Treatment Arm

\begin{tabular}{|c|c|c|}
\hline$\pi$ & \multicolumn{2}{|c|}{ No. of Patients (\%) } \\
\hline Characteristic & $\begin{array}{l}\text { Tivantinib + } \\
\text { Cetuximab } \\
(\mathrm{N}=40)\end{array}$ & $\begin{array}{c}\text { Cetuximab } \\
(\mathrm{N}=38)\end{array}$ \\
\hline Mean age (range) & $60.5(37-90)$ & $63.6(35-87)$ \\
\hline Male & $34(85.0)$ & $32(84.2)$ \\
\hline HPV $^{\text {a }}$ Statu & & \\
\hline Positive & $16(40.0)$ & $15(39.5)$ \\
\hline Negative & $24(60.0)$ & $23(60.5)$ \\
\hline Race & & \\
\hline White & $31(77.5)$ & $32(84.2)$ \\
\hline African American & $4(10.0)$ & $3(7.9)$ \\
\hline Hispanic & $1(2.5)$ & $1(2.6)$ \\
\hline Asian & $3(7.5)$ & $2(5.3)$ \\
\hline Unknown & $1(2.5)$ & $0(0.0)$ \\
\hline Number of Prior Therapies & & \\
\hline 0 & $9(22.5)$ & $5(13.2)$ \\
\hline 1 & $3(7.5)$ & $2(5.3)$ \\
\hline 2 & $12(30.0)$ & $10(26.3)$ \\
\hline 3 & $3(7.5)$ & $6(15.8)$ \\
\hline 4 & $5(12.5)$ & $4(10.5)$ \\
\hline$\sqrt{2}$ & $3(7.5)$ & $6(15.8)$ \\
\hline 6 or more & $5(12.5)$ & $5(13.2)$ \\
\hline ECOG $^{\text {b }}$ Performance Status & & \\
\hline Normal activity, asymptomatic & $17(42.5)$ & $19(50.0)$ \\
\hline Symptomatic, fully ambulatory & $23(57.5)$ & $19(50.0)$ \\
\hline
\end{tabular}

${ }^{a}$ HPV, Human Papilloma Virus. ${ }^{b}$ ECOG, Eastern Cooperative Oncology Group. 
Table 2. Best Response by Treatment Arm (Primary Endpoint)

\begin{tabular}{|l|c|c|}
\hline & \multicolumn{2}{|c|}{ No. of Patients (\%) } \\
\hline Best Response & $\begin{array}{c}\text { Tivantinib + } \\
\text { Cetuximab } \\
(\mathrm{N}=40)\end{array}$ & $\begin{array}{c}\text { Cetuximab } \\
(\mathrm{N}=38)\end{array}$ \\
\hline Complete & $1(2.5)$ & $0(0.0)$ \\
\hline Partial & $2(5.0)$ & $3(7.9)$ \\
\hline Stable disease & $15(37.5)$ & $12(31.6)$ \\
\hline Progressive disease & $15(37.5)$ & $19(50.0)$ \\
\hline $\begin{array}{l}\text { Off treatment for AE }{ }^{\mathrm{a}}<1^{\mathrm{st}} \\
\text { evaluation }\end{array}$ & $3(7.5)$ & $2(5.3)$ \\
\hline Death $<1^{\text {st }}$ evaluation & $2(5.0)$ & $0(0.0)$ \\
\hline Withdrew $<1^{\text {st }}$ evaluation & $2(5.0)$ & $1(2.6)$ \\
\hline Crossover $<1^{\text {st }}$ evaluation & $0(0.0)$ & $1(2.6)$ \\
\hline Objective Response Rate & $3 / 40=7.5 \%$ & $3 / 38=7.9 \%$ \\
\hline
\end{tabular}

${ }^{\mathrm{a}} \mathrm{AE}$, adverse event.

Table 3. Summary of Frequent Adverse Events Deemed At Least Possibly Related ${ }^{\mathrm{a}}$

\begin{tabular}{|l|c|c|c|c|}
\hline & \multicolumn{4}{|c|}{ No. of Patients (\%) } \\
\hline Characteristics & \multicolumn{2}{|c|}{ Tivantinib + Cetuximab } & \multicolumn{2}{c|}{$\begin{array}{c}\text { Cetuximab } \\
(\mathrm{N}=40)\end{array}$} \\
\hline Grade & Any & $3+$ & Any & $3+$ \\
\hline Hematologic AEs & & & & \\
\hline Anemia & $12(30)$ & $2(5)$ & $4(10.5)$ & $1(2.6)$ \\
\hline Lymphocyte count decreased & $6(15)$ & $4(10)$ & $1(2.6)$ & $1(2.6)$ \\
\hline Neutrophil count decreased & $9(22.5)$ & $5(12.5)$ & $1(2.6)$ & 0 \\
\hline Platelet count decreased & $6(15)$ & 0 & $1(2.6)$ & 0 \\
\hline White blood cell decreased & $9(22.5)$ & $5(12.5)$ & $3(7.8)$ & $1(2.6)$ \\
\hline Non-hematologic AEs & & & & \\
\hline
\end{tabular}

This article is protected by copyright. All rights reserved 


\begin{tabular}{|l|c|c|c|c|}
\hline Anorexia & $9(22.5)$ & 0 & $5(13.2)$ & 0 \\
\hline Fatigue & $18(45)$ & $3(7.5)$ & $14(37)$ & 0 \\
\hline Hypomagnesemia & $6(15)$ & 0 & $10(26)$ & $4(10.5)$ \\
\hline Nausea & $9(22.5)$ & $1(2.5)$ & $6(15.8)$ & 0 \\
\hline Rash acneiform & $19(47.5)$ & $2(5)$ & $19(50.0)$ & $2(5.3)$ \\
\hline Rash maculo-papular & $10(25)$ & $1(2.5)$ & $9(23.7)$ & 0 \\
\hline Rash/dermatitis & $6(15)$ & 0 & $8(21.0)$ & 0 \\
\hline Sinus bradycardia & $6(15)$ & 0 & $1(2.6)$ & $1(2.6)$ \\
\hline Stomatitis/pharyngitis & $8(20)$ & $3(7.5)$ & $5(13.2)$ & 0 \\
\hline Vomiting & $6(15)$ & $1(2.5)$ & $3(7.8)$ & 0 \\
\hline
\end{tabular}

${ }^{\mathrm{a}}$ Frequency cutoff for grade 1-2 AEs is 15\%, and grade 3+ occurring in $>1$ patient/s for either arm. Maximum grade per patient reported.

${ }^{\mathrm{b}} \mathrm{AE}$, adverse event.

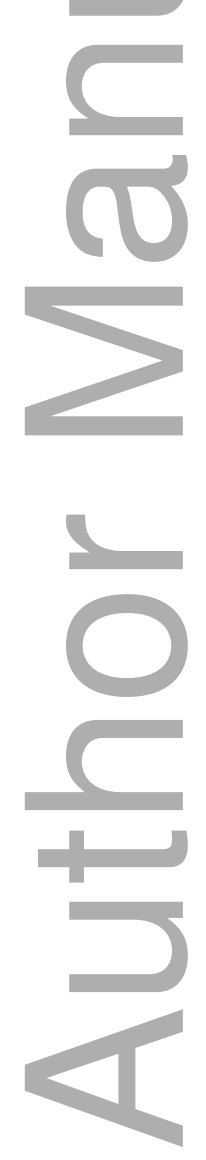




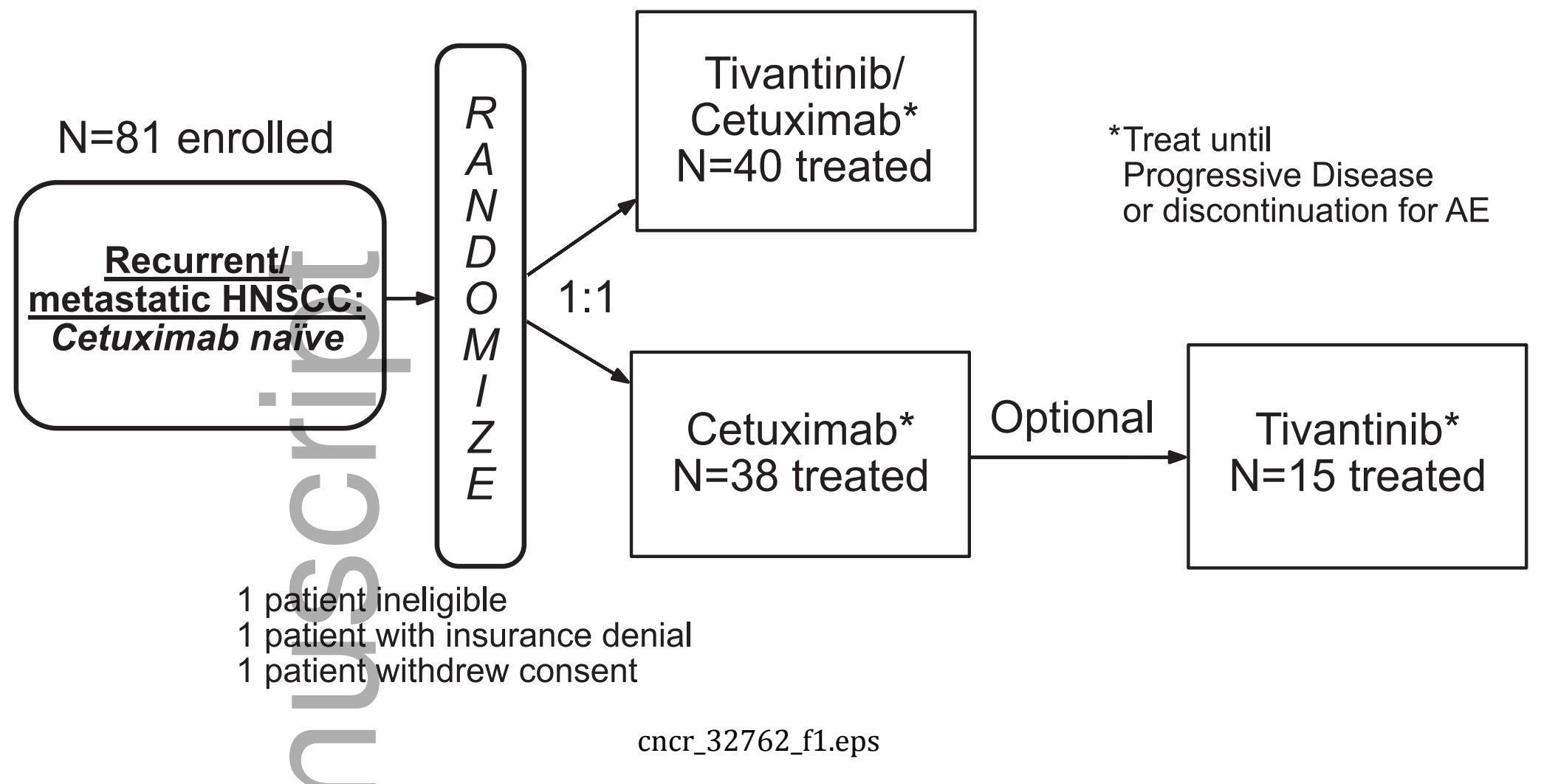


(a)

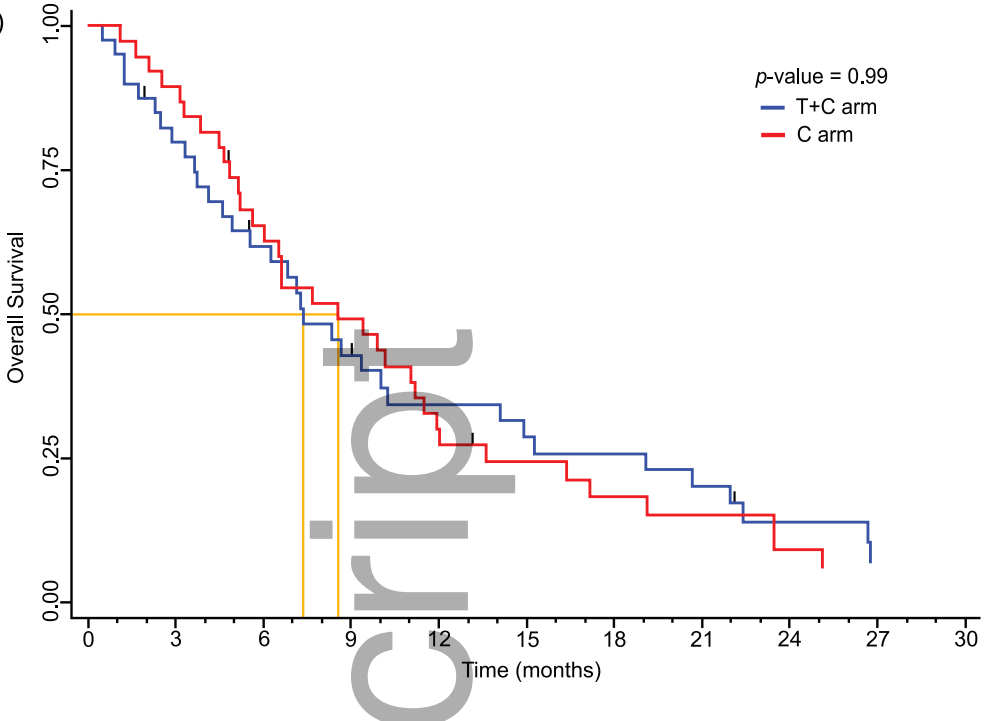

(b)

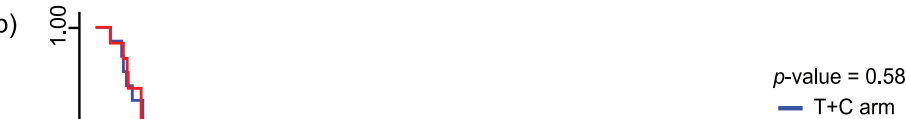

cncr_32762_f2.eps
- T+C arm

- C arm

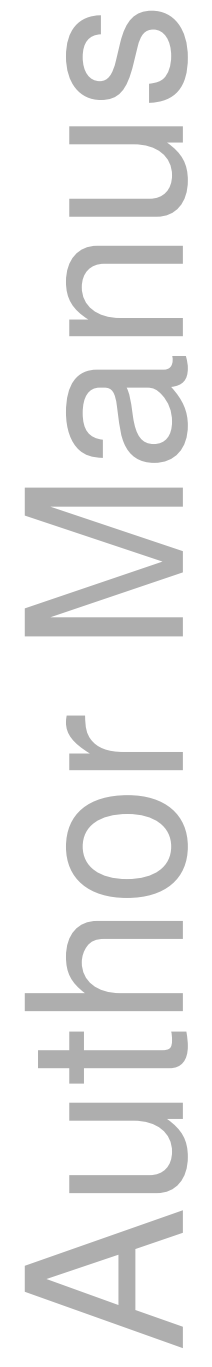

This article is protected by copyright. All rights reserved 

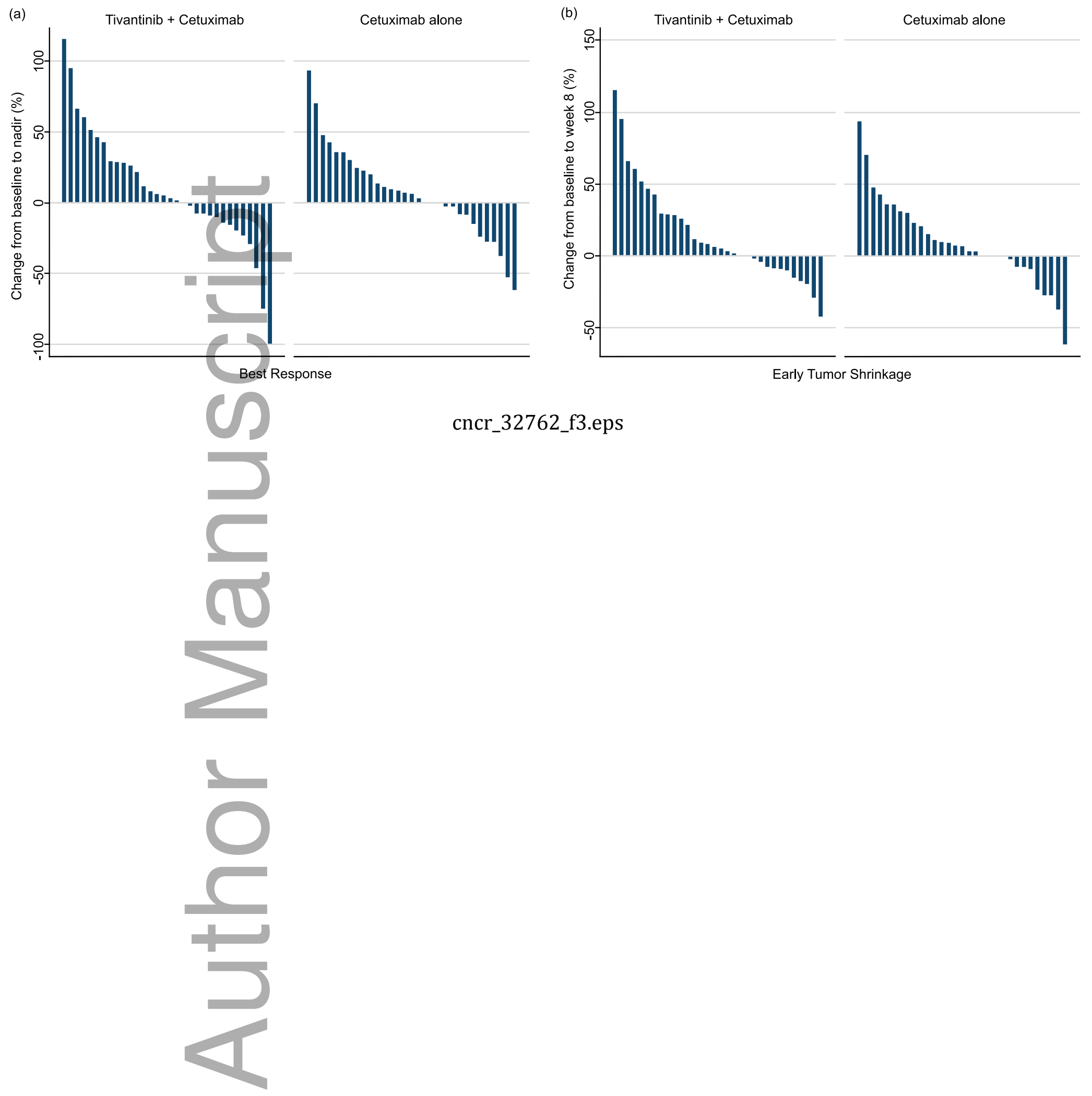

cncr_32762_f3.eps 